\title{
Genetic and phenotypic characterization of the native rabbits in Middle Egypt
}

\author{
El-Sayed Mahfouz Abdel-Kafy ${ }^{1}$, Sahar Saad El-Din Ahmed², Amira El-keredy ${ }^{3}$, Neama Ibrahim Ali ${ }^{2}$, Sherif Ramadan ${ }^{4}$ and \\ Ahmed Farid
}

1. Department of Rabbit Breeding Research, Animal Production Research Institute, Agricultural Research Centre, Dokki, Giza, Egypt; 2. Department of Cell Biology, Division research of Genetic Engineering and Biotechnology, National Research Centre, Giza, Egypt; 3. Department of Genetics, Faculty of Agriculture, Tanta University, Tanta, Egypt; 4. Department of Animal Wealth Development, Faculty of Veterinary Medicine, Benha University, Egypt. Corresponding author: Sahar Saad El-Din Ahmed, e-mail: selnahta@yahoo.com

Co-authors: EMA: sayedabdkaffy@yahoo.com,AE: elkeredyamira@yahoo.com, NIA: nehma_6@yahoo.com, SR: sherif_ramadann@yahoo.com, AF: sayedabdkaffy@yahoo.com

Received: 26-04-2018, Accepted: 06-07-2018, Published online: 14-08-2018

doi: 10.14202/vetworld.2018.1120-1126 How to cite this article: Abdel-Kafy EM, Ahmed SS, El-keredy A, Ali NI, Ramadan S, Farid A (2018) Genetic and phenotypic characterization of the native rabbits in Middle Egypt, Veterinary World, 11(8): 1120-1126.

\begin{abstract}
Aim: Native rabbits in smallholder system are considered as important genetic resources, and the present study was aimed to study the genetic and phenotypic characterization and detection of the maternal origin of the native rabbit populations located at the Middle of Egypt.
\end{abstract}

Materials and Methods: A survey of native rabbit populations was conducted in three governorates (Fayum [FY], Beni Suef [BN], and El Menia [MN]). The phenotypic characterization of rabbits included the profile body of the head, ears, eyes, neck, and legs and the coat colors. The blood samples were collected for genetic characterization based on mitochondrial (cytochrome $b$ ) and the microsatellite markers.

Results: The phenotypic characterization of the body parts in the three populations was almost similar. The body weight of the mature rabbits in MN government was significantly heaviest, and the measurements for the main body parts (body length, chest circumference, and abdominal girth) were the highest compared to the two populations. The results of mitochondrial (cytochrome $b$ ) analysis revealed that the rabbits from the three governments belonged to lineage A except one animal was recorded as lineage $\mathrm{G}$ from MN's rabbit population. The results of the microsatellite markers revealed that the genetic diversity between the three populations showed genetic interferences; however, a closer genetic relationship was observed between BN and MN than FY. The majority of the genetic diversity was the individual variability.

Conclusion: The mitochondrial lineage $A$ is the major lineage in rabbit populations in the area of the Middle Egypt understudy. The genetic populations' structure is the interferences among the three populations. A large-scale survey should be done on native rabbit populations for the sustainable management and conservation of the local breeds' genetic resources.

Keywords: microsatellite markers, middle of Egypt, mitochondrial DNA, native breed, phenotypic, rabbit.

\section{Introduction}

Native rabbit breeds by smallholder under low-input systems consider as important genetic resources because of their adaptation to harsh environmental conditions and their tolerance to a wide range of diseases. Accordingly, local breeds should be protected against any threat factors as a priority of sustainable management [1].

In Egypt, native rabbits were used early to develop many breeds such as Giza White, Baladi Red, Baladi Black, and Baladi White by selection and/or different crosses between native and exotic rabbit breeds, although the importance of the native breeds, few studies have been done concerning these rabbits [2].

Copyright: Abdel-kafy, et al. Open Access. This article is distributed under the terms of the Creative Commons Attribution 4.0 International License (http://creativecommons.org/licenses/ by/4.0/), which permits unrestricted use, distribution, and reproduction in any medium, provided you give appropriate credit to the original author(s) and the source, provide a link to the Creative Commons license, and indicate if changes were made. The Creative Commons Public Domain Dedication waiver (http:// creativecommons.org/publicdomain/zero/1.0/) applies to the data made available in this article, unless otherwise stated.
Phenotypic and genetic characterizations of the native rabbits are essential studies for the identification and improvement of the breeding programs and to help for their conservation [3]. The population genetic structure is the result of many factors such as geographical and ecological factors which may cause variation and division of the populations. Moreover, the genetic drift, gene flow, and the balance between them can also result in population genetic structure $[4,5]$. Genetic studies using mitochondrial DNA and microsatellite markers reported as essential genetics tools to explain the population structure at different temporal and spatial scales and the genetic flow among individuals within and between populations [6-9].

The purposes of this study were (1) to measure the phenotypic characterization of native rabbit populations in three governorates (Fayum [FY], Beni Suef [BN], and El Menia [MN]) at the Middle Egypt region through evaluation of external body measurements, (2) to identify the maternal origin using the mitochondrial DNA (cytochrome $b$ ), and (3) to evaluate the genetic diversity between the populations using microsatellite markers. 


\section{Materials and Methods}

\section{Ethical approval}

Experiments were carried out in accordance with the guidelines laid down by the Institutional Animal Ethics Committee and in accordance with the local laws and regulations.

\section{Animals}

A survey of the native rabbit populations was conducted in three governorates, FY, BN, and $\mathrm{MN}$ in a period from December 2017 to February 2018 (Figure-1). The phenotype data and blood samples of Native Middle Egypt rabbits (NMERs) were collected randomly from six localities of the three governorates. The phenotypic characterization of NMER was made according to Khalil [10] and included the profile body of the head, ears, eyes, neck, and legs and the coat colors. The morphological characteristics of NMER populations were taken by body weight and body dimension measurements on 83 mature rabbits. The body length was measured from atlas to the first coccygeal vertebrae, while the chest circumference was measured behind the shoulder blades and the abdominal circumference at the level of the seventh lumbar vertebrae. The ear width was from the outside to another side of the ear. Ear length was taken from the bottom to the top of the ear, and foot length was from behind the foot to start the fingers.

\section{Sample collection and DNA extraction}

A total of 83 blood samples from three rabbits populations: $\mathrm{FY}(\mathrm{n}=31), \mathrm{BN}(\mathrm{n}=31)$, and $\mathrm{MN}(\mathrm{n}=21)$ were used for genetic characterization. Blood samples were collected into $5 \mathrm{~mL}$ Vacutainer tubes containing EDTA as an anticoagulant and stored at $4^{\circ} \mathrm{C}$ until molecular analyses were performed. DNA was extracted from rabbit blood samples using Chelex $100^{\circledR}$ according to a slight modification of a protocol of Welsh and McClelland [11].

\section{Mitochondrial genotyping}

Two primers of the cytochrome $b$ gene were used according to Branco et al. [12] (CBF: 5'-ATGACCAACATTCGCAAAACC-3' and CBR: 5'-TGTCTCAGGGAGAACTATCTCC-3'). The polymerase chain reaction (PCR) was performed in a final volume of $25 \mu \mathrm{L}$ containing: $200 \mu \mathrm{M}$ of dNTPs, $0.2 \mu \mathrm{M}$ of each primer, $1 \mathrm{U}$ Taq polymerase (H. T. Biotechnology), and $1 \mu \mathrm{L}$ of DNA extract. The PCR program consisted of 4 min of denaturation at $94^{\circ} \mathrm{C}$, followed by 40 cycles of $1 \mathrm{~min}$ at $94^{\circ} \mathrm{C}, 1 \mathrm{~min}$ at $55^{\circ} \mathrm{C}$, and $1 \mathrm{~min} 30 \mathrm{~s}$ at $72^{\circ} \mathrm{C}$, plus a final extension of $10 \mathrm{~min}$ at $72^{\circ} \mathrm{C}$. The PCR products were digested with AluI restriction enzymes (Promega, France), following the manufacture instruction. The PCR products and 100-bp DNA ladder (Promega Corporation, France) were electrophoresed on $2 \%$ agarose gel (Invitrogen Ultrapure ${ }^{\mathrm{TM}}$ Agarose $^{\circledR}$, Carlsbad, USA). The amplified products were visualized in the gel documentation apparatus, photographed and analyzed according to the number and the size of fragments resulted from restriction enzyme digestion.

\section{Microsatellite genotyping}

Eight microsatellite markers were used for genotyping analysis (Sat2, Sat3, Sat5, Sat7, Sat8, Sat12, Sat13, and Sat16) [13-15]. PCR reactions were performed in a final volume of $15 \mu \mathrm{L}$ that contained 200 $\mu \mathrm{M}$ dNTPs, 0.2-0.4 $\mu \mathrm{M}$ of each primer, 0.325 U Taq polymerase (H. T. Biotechnology), and $0.5 \mu \mathrm{L}$ of DNA extract. PCR programs involved 5 min of initial denaturation at $95^{\circ} \mathrm{C}$, followed by 30 cycles of $30 \mathrm{~s}$ at $95^{\circ} \mathrm{C}$, $30 \mathrm{~s}$ between $55^{\circ} \mathrm{C}$ and $60^{\circ} \mathrm{C}$, and $30 \mathrm{~s}$ at $72^{\circ} \mathrm{C}$, followed by a final extension step of $10 \mathrm{~min}$ at $72^{\circ} \mathrm{C}$. The

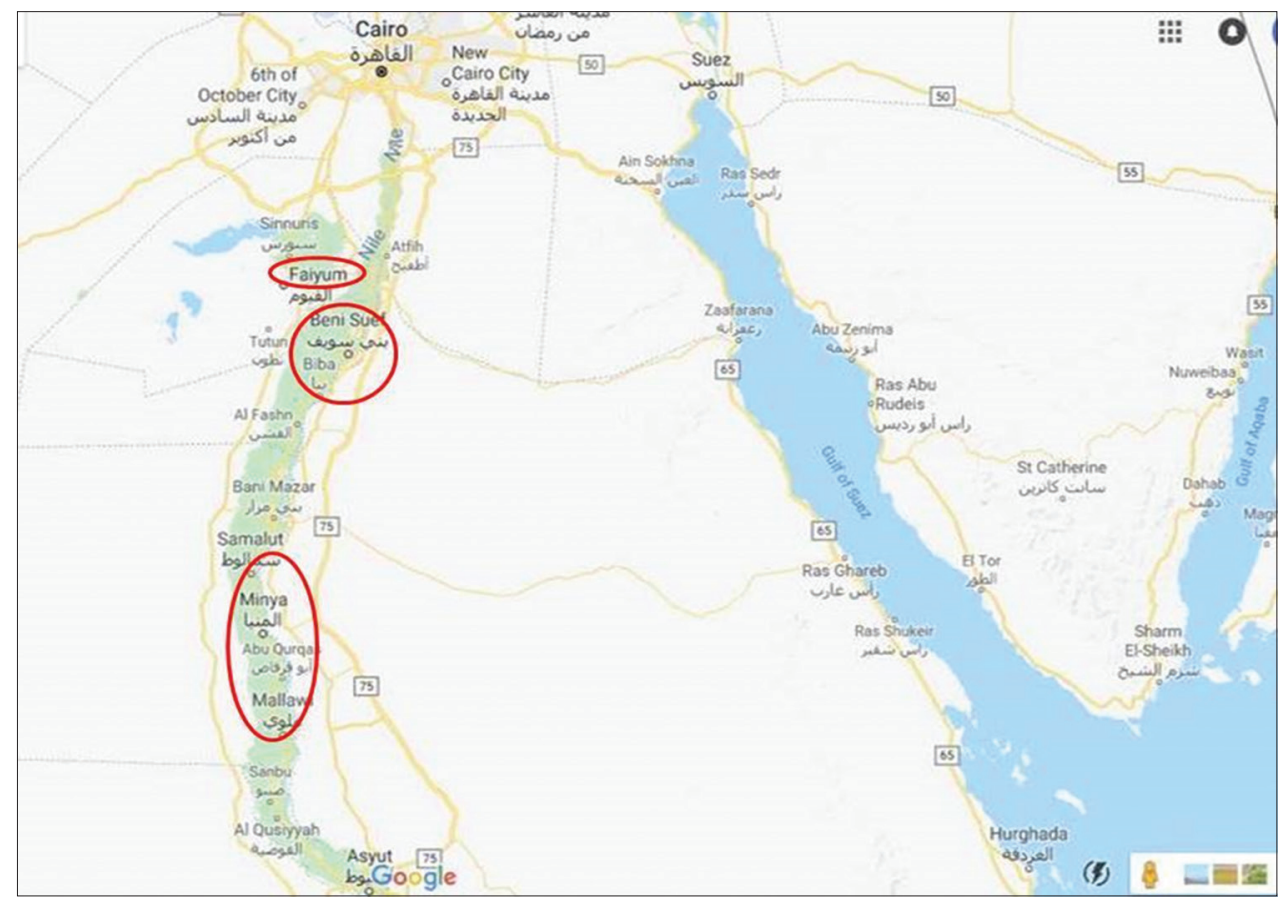

Figure-1: The geographical locations of Fayum, Beni Suef, and El Menia Governorates in Egypt. 
PCR products were separated on denaturing electrophoresis in $3 \%$ polyacrylamide gels containing urea, and bands were visualized by rapid silver staining [16].

\section{Statistical analysis}

Least square means for body weight and body dimension measurements were estimated using the GLM procedure of SAS version 9.1.3 (SAS Institute Inc., Cary, $\mathrm{NC}$, USA). The model used was $\mathrm{Yij}=\mu+\mathrm{Pi}+\mathrm{eij}$, where Yij=any observation of rabbit within $\mathrm{i}^{\text {th }}$ populations $(\mathrm{P})$, $\mu=$ overall mean, $\mathrm{P} i=$ the effect of the populations, $\mathrm{i}=1,2$, and 3 , and eij=the random error. Significant differences between the populations were defined by Duncan test.

Genetic diversity was evaluated by calculating the observed and effective number of alleles $\left(N_{o}\right.$ and $\left.N_{e}\right)$, heterozygosity observed and expected $\left(H_{o}\right.$ and $\left.H_{e}\right)$ using GENALEX software version 6.0 [17]. Polymorphic information content (PIC) was assessed using CERVUS software version 3 [18]. Pairwise $F_{S T}$ [19] in addition to F-statistics $\left(F_{I S}, F_{S T}\right.$, and $\left.F_{I T}\right)$ across the three studied populations were calculated using the GENEPOP software version 3.4 [20]. Genetic distances among the three studied populations were evaluated by Reynolds genetic distance [21]. A neighbor-joining (NJ) phylogenetic tree was constructed based on the Reynolds genetic distance [22]. These processes were conducted using POPULATIONS version 1.2.30 software; pairwise comparisons of the 20 runs of each $\mathrm{K}$ value were done with 20 permutations using CLUMPP software [23].

The STRUCTURE software was investigated for the analysis of the genetic structure and clustering the three studied rabbit populations, 20 runs for each different value of $K$ with 50,000 iterations following a burn-in period of 50,000. The clustering pattern with the highest $H$ value was graphically displayed for the selected $K$ value using DISTRUCT software [24].

\section{Results and Discussion}

\section{Phenotypic characterization}

The body profile showed that the base in the rump was wide, round, and full appearance while at shoulders apart are low and narrow, but they are sturdy (Figure-2: Photo-1). The head was between medium and small in size, but it was long and narrow in proportion. The profile of the head was sloped from the base of the ears down to the nose in a line which was almost straight. The ears were relatively long. The eyes were large and protruding (Figure-2: Photo-2). The neck was short but visible. Legs were strong, straight with a medium length. The coat colors included different models: Grayish, brown, and white (Figure-2: Photo-3a and b) and sometimes gray or red sprinkled throughout the coat. Another model, the underside of the body, was pale-gray or black or brown, while the upper side of the body was white (Figure-2: Photo-3c). The phenotypic results revealed that the NMER in the three populations was almost similar and very close to the rabbit in Malta [25].

\section{Body weight and body dimensions}

The size of the NMER in the three populations was small to medium. The mean of the body weights, body length, chest circumference, and abdominal girth of NMER is shown in Table-1. The body weights of FY and BN governments were closer to the Dwarf rabbit in Italy which ranged from 1953 to $1850 \mathrm{~g}$ [26], while the body length was medium and the chest circumference was similar to that of the local rabbit breeds in Lebanon [27]. The mean of the body weights of the mature rabbits in MN government was significantly heaviest, and the measurements for the main body parts (body length, chest circumference, and abdominal girth) were highest among the three studied populations. The phenotypic characterization of the BN government was significantly measured less than other populations.

\section{Genetic characterizations}

\section{Mitochondrial analysis}

The results of the mitochondrial cytochrome $b$ revealed that the overall NMERs carried lineages A, while lineage $G$ was found as single case from $\mathrm{MN}$
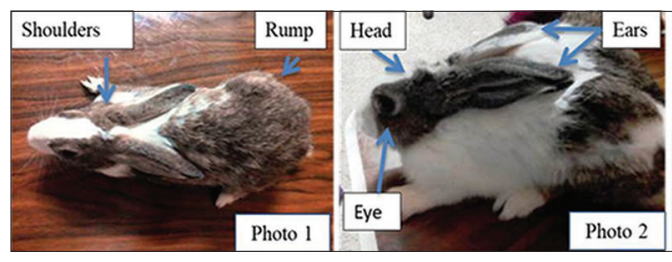
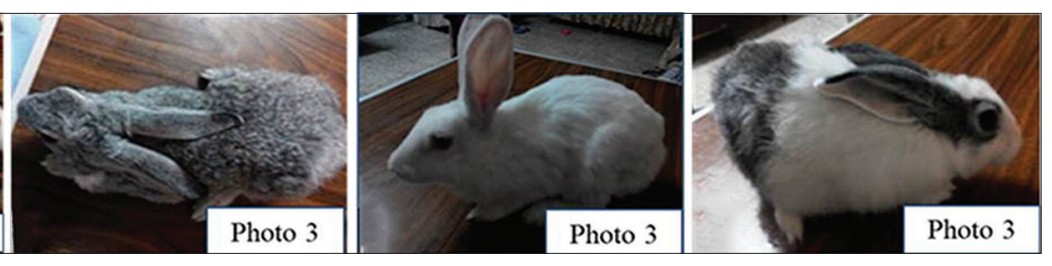

Photo 3

Figure-2: The native Middle Egypt rabbit phenotypes.

Table-1: Measurements of body weights and body dimensions of NMER rabbit populations.

\begin{tabular}{|c|c|c|c|c|c|c|c|}
\hline $\begin{array}{l}\text { Geographical } \\
\text { location }\end{array}$ & $\begin{array}{l}\text { Weight } \\
\text { (g) }\end{array}$ & $\begin{array}{l}\text { Body length } \\
(\mathrm{cm})\end{array}$ & $\begin{array}{c}\text { Chest } \\
\text { circumference } \\
(\mathbf{c m})\end{array}$ & $\begin{array}{l}\text { Abdominal } \\
\text { girth } \\
(\mathrm{cm})\end{array}$ & $\begin{array}{l}\text { Ear width } \\
\quad(\mathrm{cm})\end{array}$ & $\begin{array}{l}\text { Ear length } \\
\quad(\mathrm{cm})\end{array}$ & $\begin{array}{c}\text { Foot length } \\
(\mathrm{cm})\end{array}$ \\
\hline$\overline{F Y}$ & $1691.9 \pm 55.8^{b}$ & $32.8 \pm 0.35^{\mathrm{ab}}$ & $24.2 \pm 0.30^{\mathrm{b}}$ & $24.8 \pm 0.48^{b}$ & $5.72 \pm 0.04$ & $9.80 \pm 0.08$ & $6.62 \pm 0.08$ \\
\hline $\mathrm{BN}$ & $1538.6 \pm 55.8^{b}$ & $32.5 \pm 0.35^{b}$ & $23.0 \pm 0.30^{\mathrm{b}}$ & $22.8 \pm 0.48^{b}$ & $5.80 \pm 0.04$ & $10.17 \pm 0.08$ & $6.51 \pm 0.08$ \\
\hline $\mathrm{MN}$ & $2062.9 \pm 68.2^{\mathrm{a}}$ & $35.2 \pm 0.41^{a}$ & $27.4 \pm 0.36^{a}$ & $29.9 \pm 0.55^{a}$ & $6.14 \pm 0.06$ & $9.91 \pm 0.12$ & $6.56 \pm 0.13$ \\
\hline Mean \pm SE & $1662.9 \pm 62.8$ & $32.9 \pm 0.38$ & $24.0 \pm 0.33$ & $24.5 \pm 0.52$ & $5.7 \pm 0.05$ & $9.9 \pm 0.09$ & $6.5 \pm 0.09$ \\
\hline
\end{tabular}

Means with different superscript letters are significantly different. NMER=Native Middle Egypt rabbit, BN=Beni Suef, $\mathrm{MN}=\mathrm{El}$ Menia, $\mathrm{FY}=$ Fayum, SE=Standard error 
(Figure-3). The current study considered as the first detection of the maternal origin in the native Egyptian rabbit populations. The data generated here provide valuable information related to the common ancestor of the rabbits between many places in Middle Egypt according to cytochrome $b$ analysis. Existence of mitochondrial lineage A as the major lineage in Egyptian rabbit populations may support the theory that rabbits were transferred from southwest of the Iberian Peninsula to Egypt and North of Africa zone, where lineage A is predominant in the subspecies Oryctolagus cuniculus algirus inhabiting the Southwest of the Iberian Peninsula and lineage $\mathrm{B}$ is predominant in O. cuniculus inhabiting the northeast of the Peninsula [28].

\section{Microsatellites analysis}

The genetic diversity of the NMER populations shows that the alleles detected across eight microsatellite loci in the three studied populations were 46 (Table-2). The number of observed alleles $\left(N_{o}\right)$ ranged between 3.64 and 10 with an average 6.125. The majority of the markers were characterized by high allelic values per locus except for Sat2 and Sat7. The polymorphism information content per locus (PIC) index which is revealed the degree of microsatellite loci polymorphism recorded higher values exceeding 0.5 in all markers except for Sat2 (0.326) and Sat7 (0.474). The total population heterozygosity $\left(H_{e}\right)$ of microsatellite loci ranged between 0.340 and 0.878 with an average 0.705 . These results are relatively higher than the study of Xin-Sheng et al. [29] in Wan line Angora rabbit which was 4.5 for $N_{o}, 0.680$ for $H_{e}$, and 0.642 for PIC. However, our results were lower than reported by El-Aksher et al. [30] whose recorded average values for $H_{o}(0.650), H_{e}(0.800)$, and PIC $(0.760)$ across four Egyptian rabbit populations different than the rabbit populations understudy. The studied microsatellite markers deviated significantly from Hardy-Weinberg equilibrium $(\mathrm{p}<0.001)$ except Sat 2 and Sat7. The results suggested that the rabbits under study might be a non-random mating or undergo certain kind of selection for some favorable traits.

\section{Genetic diversity within population}

The mean value of $N_{o}$ and effective $N_{e}$ numbers of alleles, observed $\left(H_{o}\right)$ and expected $\left(H_{e}\right)^{e}$ heterozygosities, and the fixation coefficient of an individual

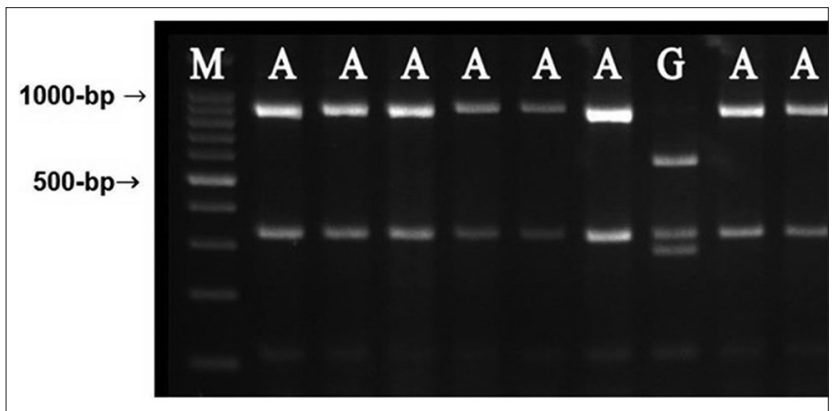

Figure-3: Genotypic patterns of cytochrome $b$ in the native Middle Egypt rabbits, $M$ is a $100-b p$ DNA ladder.

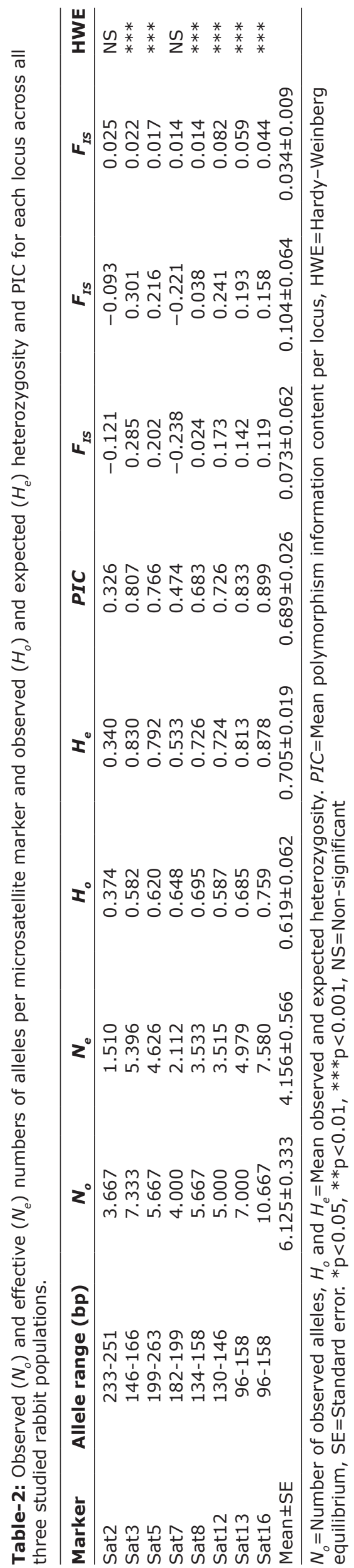

Veterinary World, EISSN: 2231-0916 
within a subpopulation $\left(F_{I S}\right)$ are shown in Table-3. The highest value of $N_{o}(6.625)$ and $N_{e}(4.327)$ was recorded for FY population, while the lowest values $\left(N_{o}=5.625\right.$ and $\left.N_{e}=4.008\right)$ were recorded for $\mathrm{MN}$ rabbit population. $\stackrel{e}{\mathrm{BN}}$ and $\mathrm{MN}$ populations showed higher expected heterozygosity $\left(H_{e}=0.715\right.$ and 0.705 , respectively) than FY population $\left(H_{e}=0.693\right)$. The higher observed heterozygosity in the two populations could be attributed to several crosses due to human activities such as exchanging and marketing between different villages. The result could be supported by the higher performance traits of the body weight and dimensions observed in MN population (Table-1) which might be a result of hybrid vigor due to several mating and crosses.

The results of the mean number of the observed alleles were $N_{o}=6.125$ in NMER which is lower than that observed in another Egyptian rabbit populations $\left(N_{o}=6.75\right)$ [30]. The value of $F_{I S}$ among the three rabbit populations was 0.071 which is relatively lower $(0.172)$ than that reported in the Spanish rabbit populations by Grimal et al. [31]. On the other hand, the observed heterozygosity of the NME populations recorded higher values compared to what have been reported in Middle Egyptian native rabbit breeds by Abdel-Kafy et al. [4], while it was closer to the values of Tunisian's rabbits $\left(H_{o}\right.$ ranging from 0.365 to $0.482)$ [32] and Spanish breeds $\left(H_{o}\right.$ ranging from 0.36 to 0.48 ) [31]. The variation between the results of this study and Abdel-Kafy et al. [4] is probably due to the sampling process, where they collected from eight geographical locations very near to each other, and each location was considered as a population, while in this study, the samples of each governorate were considered as a one population.

\section{Genetic diversity between populations}

The NJ phylogenetic tree of the investigated rabbit populations showed the close relationship between $\mathrm{MN}$ and BN than FY (Figure-4). This could be attributed to the high connection between $\mathrm{MN}$ and $\mathrm{BN}$ governorates because of the short geographical distance and no natural barriers between them (Figure-1).

The pairwise $F_{S T}$ values among the three populations were ranged from 0.024 to 0.028 . The $F_{S T}$ values between populations indicated a generally low level of genetic differentiation. The highest $F_{S T}$ value (0.028) was recorded between MN and FY, while the lowest value (0.024) was between $\mathrm{BN}$ and $\mathrm{MN}$ government (Table-4). Overall, the genetic distance between the three populations was small which suggested that the three populations were closely related and had a common ancestor. Comparing with the previous studies, the genetic distance between the three populations was lower than that reported for Tunisian rabbit populations [32].

The investigated population structure using the Bayesian approach revealed that the most structural clustering pattern was shown at the number of clusters $(K)=2$ where the FY population incompletely separated in the first cluster, while BN and MN clustered together showing admixed mosaic cluster with high interferences between them (Figure-5). In the case of $K=3$, all populations were the interferences and not detected in separate clusters. This result was confirmed by individual phylogenetic tree of the investigated 83 rabbits (Figure-4). This finding could be related to the geographical location of FY Governorate away in the

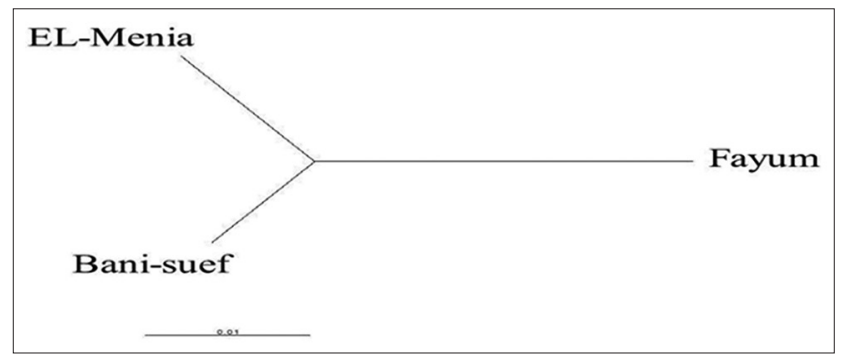

Figure-4: Neighbor-joining population phylogenetic tree for the three studied rabbit populations.

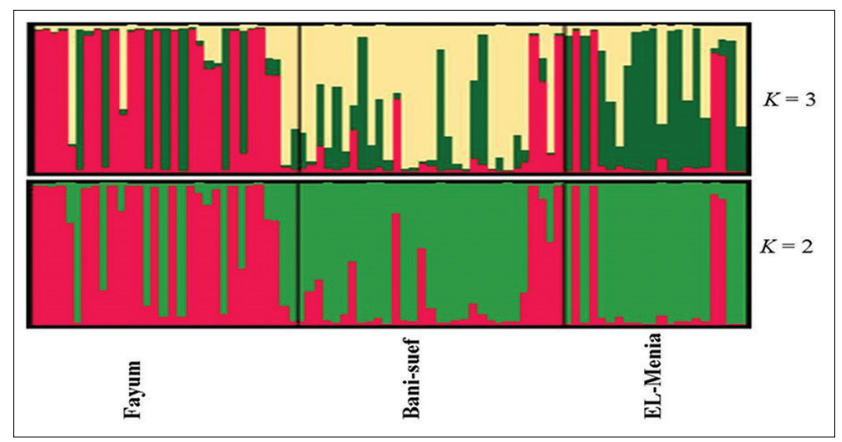

Figure-5: Structure clustering of the three native Middle Egypt rabbit populations obtained for $K=2$ and 3 . The $K$ is the cluster number.

Table-3: Observed $\left(N_{0}\right)$ and effective $\left(N_{0}\right)$ numbers of alleles and mean observed $\left(H_{0}\right)$ and expected $\left(H_{e}\right)$ heterozygosities and fixation coefficient of an individual within a subpopulation $\left(F_{I S}\right)$ per population rabbits.

\begin{tabular}{lcccccc}
\hline Geographical location & $\mathbf{N}$ & $\mathbf{N}_{\boldsymbol{o}} \pm \mathbf{S E}$ & $\mathbf{N}_{\mathbf{e}} \pm \mathbf{S E}$ & $\boldsymbol{H}_{o} \pm \mathbf{S E}$ & $\boldsymbol{H}_{e} \pm \mathbf{S E}$ & $\mathbf{F}_{\text {Is }} \pm \mathbf{S E}$ \\
\hline FY & 31 & $6.625 \pm 1.322$ & $4.327 \pm 0.930$ & $0.625 \pm 0.058$ & $0.693 \pm 0.072$ & $0.028 \pm 0.101$ \\
BN & 31 & $6.125 \pm 0.515$ & $4.134 \pm 0.644$ & $0.577 \pm 0.041$ & $0.715 \pm 0.055$ & $0.161 \pm 0.066$ \\
MN & 21 & $5.625 \pm 0.653$ & $4.008 \pm 0.576$ & $0.655 \pm 0.048$ & $0.705 \pm 0.067$ & $0.024 \pm 0.041$ \\
Total & & $6.125 \pm 0.505$ & $4.156 \pm 0.405$ & $0.619 \pm 0.028$ & $0.705 \pm 0.036$ & $0.071 \pm 0.043$ \\
\hline
\end{tabular}

Number of individuals $(\mathrm{N})$, number of allele $\left(N_{o}\right)$, of effective number of allele $\left(N_{e}\right)$, observed heterozygosity $\left(H_{o}\right)$, and expected heterozygosity $\left(H_{e}\right)$ of local Middle Egypt rabbit populations. BN=Beni Suef, MN=El Menia, $\mathrm{FY}=\mathrm{Fayum}$ 
Table-4: Reynolds genetic distances (above diagonal) and pairwise $F_{S T}$ (below diagonal) among the three studied rabbit populations.

\begin{tabular}{lccc}
\hline Population & FY & BN & MN \\
\hline FY & & 0.095 & 0.09 \\
BN & 0.026 & & 0.083 \\
MN & 0.028 & 0.024 & \\
\hline
\end{tabular}

$\mathrm{BN}=$ Beni Suef, $\mathrm{MN}=\mathrm{El}$ Menia, $\mathrm{FY}=$ Fayum

Northeast of the Nile River. Moreover, the BN and $\mathrm{MN}$ governorates are located on the river Nile where the human activities like marketing can also shape the rabbit population structure as the rabbit genetic diversity in its native distribution is the result of an ensemble of factors, from geographical and ecological, to behavioral and molecular, that hierarchically interact through time and space [32].

\section{Conclusion}

The phenotypic characterization of the NMER populations showed that the body weights, body length, chest circumference, and abdominal girth of $\mathrm{MN}$ rabbit population recorded the highest values among the three populations under the study. The major lineage in the three populations was lineage A. The genetic diversity between the three populations showed a closer genetic relationship between BN and $\mathrm{MN}$ rabbit populations than FY, while the result of the genetic distance between the three populations was small which suggested that the three populations were closely related and had a common ancestor. The majority of the genetic diversity was explained by individual variability. A large-scale survey should be done on native rabbit populations for developing sustainable genetic improvement and conservation programs of the local breeds' genetic resources.

\section{Authors' Contributions}

EMA and SSA planned and designed the study. AE, NIA, SR, and AF collected the blood samples and provided the help for statistical analysis. NIA, AE, and SSEA carried out the laboratory work. SR and SS provided the help for the data analysis and interpretation of the laboratory results. EMA drafted the manuscript. All authors participated in the revision of the manuscript. All authors read and approved the final manuscript.

\section{Acknowledgments}

We would like to express our thanks to rabbit breeders for helping the authors to evaluate the phenotypic measurements and to supply rabbit blood samples. The authors acknowledge the Animal Production Research Institute and National Research Centre (Department of Cell Biology, Division research of Genetic Engineering and Biotechnology) for providing the opportunity to develop the research work. Furthermore, the authors would like to thank Tanta University (Faculty of Agriculture, Biotechnology Laboratory, Animal production Department) and
Benha University (Faculty of Veterinary Medicine, Department of Animal Wealth Development) for the facilities required for the performance of the research study. The study was self-funded by authors.

\section{Competing Interests}

The authors declare that they have no competing interests.

\section{References}

1. Nyamushamba, G., Mapiye C., Tada O., Halimani, T. and Muchenje V. (2017) Conservation of indigenous cattle genetic resources in Southern Africa's smallholder areas: Turning threats into opportunities. Asian Aust. J Anim. Sci, 30: 603-621.

2. El-Khishin, A., Badreldin, A., Oloufa, M. and Kheireldin, M. (1951) Growth development and litter size in two breeds of rabbits. Bull. Fac. Agric. Cairo Univ. Egypt., 2: 29.

3. Galal, E. and Khalil, M. (1994) Development of rabbit industry in Egypt. Cah. Options Mediterr. Cah., 8: 43-56.

4. Abdel-Kafy, E.M., Ghaly, I.S., Ben larbi, M., Ahmed, S.S., Badaw, I.Y.K. and Hassan, N.S. (2016) Genetic diversity and phenotype characterization of native rabbit in MiddleEgypt. J. New Sci., 16: 1312-1320.

5. Oseni, S. and Oke, O. (2012) Morphological and Quantitative Characteristics of a Composite Rabbit Population in Backyard Systems in Southwestern Nigeria. Proceedings $10^{\text {th }}$ World Rabbit Congress SO, Oseni. Sharm El-Sheikh-Egypt. p223-227.

6. Alda, F. and Doadrio, I. (2014) Spatial genetic structure across a hybrid zone between European rabbit subspecies. Peer J., 2: 582-606.

7. Fenderson, L.E., Kovach, A.I., Litvaitis, J.A., O'Brien, K.M., Boland, K.M. and Jakubas, W.J. (2014) A multiscale analysis of gene flow for the New England cottontail, an imperiled habitat specialist in a fragmented landscape. Ecol. Evol., 4: 1853-1875.

8. Abdel-Mawgood, A.L. (2012) DNA Based Techniques for Studying Genetic Diversity, Genetic Diversity in Microorganisms Mahmut Caliskan, IntechOpen, London, UK, Available from https://www.intechopen. $\mathrm{com} / \mathrm{books} /$ genetic-diversity-in-microorganisms/ dna-based-techniques-for-studying-genetic-diversity. Last accessed on 03-08-2018.

9. Berkman, L.K., Nielsen, C.K., Roy, C.L. and Heist, E.J. (2015) Comparative genetic structure of sympatric leporids in southern Illinois. J. Mammal., 96: 552-563.

10. Khalil, M. (2010) Descriptive model for rabbit genetic resources data bank. World Rabbit Sci., 1: 113-118.

11. Welsh, J. and McClelland, M. (1990) Genomic fingerprinting produced by PCR with consensus tRNA gene primers. Nucleic Acids Res., 19: 861-866.

12. Branco, M., Ferrand, N. and Monnerot, M. (2000) Phylogeography of the European rabbit (Oryctolagus cuniculus) in the Iberian Peninsula inferred from RFLP analysis of the cytochrome $b$ gene. Heredity, 85: 307 .

13. Mougel, F., Mounolou, J. and Monnerot, M. (1997) Nine polymorphic microsatellite loci in the rabbit, Oryctolagus cuniculus. Anim. Genet., 28: 59.

14. Rico, C., Rico, I., Webb, N., Smith, S., Bell, D. and Hewitt, G. (1994) Four polymorphic microsatellite loci for the European wild rabbit, Oryctolagus cuniculus. Anim. Genet., 25: 367-367.

15. Surridge, A., Bell, D., Rico, C. and Hewitt, G. (1997) Polymorphic microsatellite loci in the European rabbit (Oryctolagus cuniculus) are also amplified in other lagomorph species. Anim. Genet., 28: 302-305.

16. Sanguinetti, C.J., Dias, N.E. and Simpson, A. (1994) Rapid silver staining and recovery of PCR products separated on 
polyacrylamide gels. Biotechniques, 17: 914-921.

17. Peakall, R. and Smouse, P. (2012) GenAlEx 6.5: Genetic analysis in Excel. Population genetic software for teaching and research-an update. Bioinformatics, 28: 2537-2539.

18. Kalinowski, S.T., Taper, M.L. and Marshall, T.C. (2007) Revising how the computer program CERVUS accommodates genotyping error increases success in paternity assignment. Mol. Ecol., 16: 1099-1106.

19. Peter, B.M. (2016) Admixture, population structure, and F-statistics. Genetics, 202: 1485-1501.

20. Raymond, M. (1995) GENEPOP (version 1.2): Population genetics software for exact tests and ecumenism. J. Hered., 86: $248-249$

21. Reynolds, J., Weir, B.S. and Cockerham, C.C. (1983) Estimation of the coancestry coefficient: Basis for a shortterm genetic distance. Genetics, 105: 767-779.

22. Saitou, N. and Nei, M. (1987) The neighbor-joining method: A new method for reconstructing phylogenetic trees. Mol. Biol. Evol., 4: 406-425.

23. Rosenberg, N.A. (2004) DISTRUCT: A program for the graphical display of population structure. Mol. Ecol. Resour., 4: 137-138.

24. Jakobsson, M. and Rosenberg, N.A. (2007) CLUMPP: A cluster matching and permutation program for dealing with label switching and multimodality in analysis of population structure. Bioinformatics, 23: 1801-1806.

25. Gauci-Maistre, J. (1999) “Tax-xiber"-The indigenous rabbit of Malta. Cah. Options Méditerr., 41: 183-187.

26. Zotte, A.D., Ricci, R., Sartori, A., Lukefahr, S. and Paci, G. (2013) Body morphometric development during growth and maturity of coloured dwarf rabbits available in the Italian market. World Rabbit Sci., 21: 227-233.

27. Hajj, E., Boutros, C. and Abi, S.J. (2002) The Baladi rabbits (Lebanon). Options Méditerr. B Etud. Rec. (CIHEAM), 38: 157-161.

28. Biju-Duval, C., Ennafaa, H., Dennebouy, N., Monnerot, M., Mignotte, F., Soriguer, R.C., El Gaaïed, A., El Hili, A. and Mounolou, J.C. (1991) Mitochondrial DNA evolution in lagomorphs: Origin of systematic heteroplasmy and organization of diversity in European rabbits. J. Mol. Evol., 33: $92-102$

29. Xin-sheng, W., Tian-Wen, W., Hui-Ling, Z., Long, C.G., Qi, X., Jin-Hua, C., Xiu-Bai, Z. and Guo-Hong, C. (2008) Correlation analysis of wool yield in wan line Angora rabbits using microsatellite DNA markers. J. Biol. Sci., 8: 679-682.

30. El-Aksher, S.H., Sherif, H., Khalil, M., El-Garhy, H.A. and Ramadan, S. (2017) Molecular analysis of a new synthetic rabbit line and their parental populations using microsatellite and SNP markers. Gene. Rep., 8: 17-23.

31. Grimal,A., Safaa, H., Saenz-de-Juano, M., Viudes-de-Castro, M., Mehaisen, G., Elsayed, D., Lavara, R., Marco-Jiménez, F. and Vicente, J. (2012) Phylogenetic Relationships Among Four Egyptian and one Spanish Rabbit Populations Based on Microsatellite Markers. Proceedings $10^{\text {th }}$ World Rabbit Congress. p3-6.

32. Larbi, M.B., San-Cristobal, M., Chantry-Darmon, C. and Bolet, G. (2014) Population structure in Tunisian indigenous rabbit ascertained using molecular information. World Rabbit Sci., 22: 223-230. 